\title{
Importance of experimental measurements and simulations for "sludge-to-energy" systems
}

\author{
L. Houdkova, J. Boran, T. Elsäßer \& P. Stehlik \\ Institute of Process and Environmental Engineering, \\ Brno University of Technology (UPEI VUT), Czech Republic
}

\begin{abstract}
It has recently been found that sewage sludge is a suitable and widely applicable alternative energy source which belongs to renewables. Several options for "sludge-to-energy" exploitation in sludge treatment sections of waste-water-treatment plants (WWTP) can be considered. Among the key factors influencing the choice of sludge treatment technology are the sludge heating value, its composition and specifically, the fraction of organic compounds. A crucial parameter in evaluation of mass and energy fluxes is the level of attainable de-watering, which depends on several factors which should be investigated.

Thermal properties of sewage sludge belong among the most important input data for a calculation of characteristic parameters of a heat exchanger for sludge preheating. Results of measurements, performed in order to obtain the necessary data, are presented in this paper. Temperature dependences of the following sludge properties have been measured: dynamic viscosity, density and specific heat capacity for temperature range from $20^{\circ} \mathrm{C}$ to $50^{\circ} \mathrm{C}$. Sludge samples were taken from two sewage plants which differ in the type of inlet waste water. The results of measurement are presented in diagrams. Temperature dependences of the above-mentioned quantities were measured for digested, mixed-raw and pasteurized sludge. Acquired data were used for preliminary assessment of heat exchanger "water-sludge".

This novel type of heat exchanger will be used for determining the influence of temperature on the degree of sewage sludge dewatering. For this specific task, a "made-to-measure" heat exchanger had to be designed. From the evaluated alternatives choices, a conception of a helical plate heat exchanger has been selected. The application of this heat exchanger and dependence of heat exchanger design on sludge properties are discussed.

Keywords: sludge, heat capacity, density, dynamic viscosity.
\end{abstract}




\section{1 "Sludge-to-Energy" utilization}

Sludge is created as a spin-off product during waste water clarification. After the sludge thickening stage at the waste water treatment plant the dry matter content of mixed raw sludge ranges from $5 \%$ to $8 \%$. Figure 1 : shows the layout of a typical waste water treatment plant.

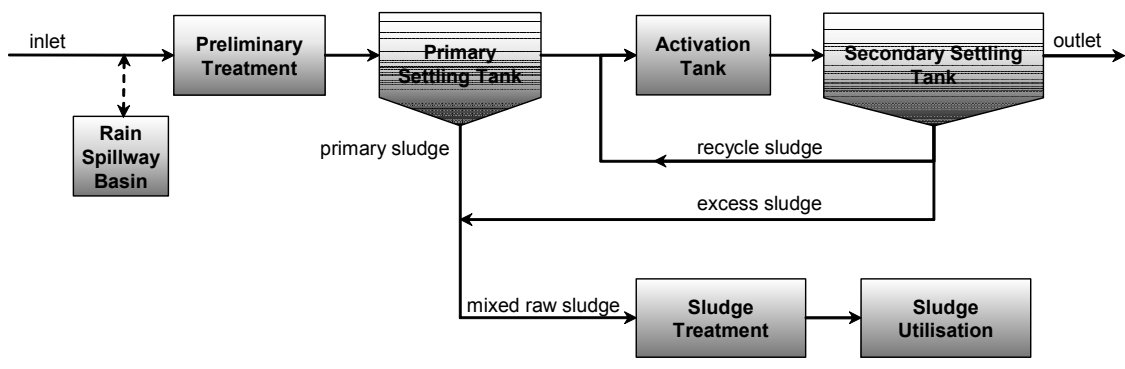

Figure 1: Flowsheet of waste water treatment plant (WWTP).

The most commonly used sludge treatment is stabilization in digesters and afterwards sludge dewatering. Using conventional means of dewatering, the dry matter content of digested sludge of about $25 \%$ to $35 \%$ is achieved. During digestion energy contained in the organic part of the sludge is converted into biogas. This leads to a reduction of lower heating value.

Another possibility is to use dewatered mixed raw sludge for direct combustion. During this process not only the sludge stabilization, but also complete energy utilization is achieved.

The most important parameter, as far as energy efficient sludge combustion is concerned, is the heating value which depends on the water content and the composition of the sludge respectively.

In Figure 2: the dependence of a lower heating value on dry matter content of mixed raw sludge is shown. From this figure it is obvious that in order to increase a lower heating value the amount of water in the sludge needs to be reduced.

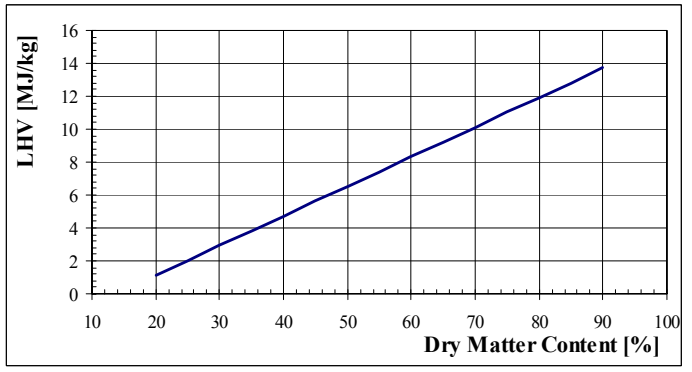

Figure 2: Lower heating value vs. dry matter content for mixed raw sludge. 
In order to achieve the goal of sludge incineration without auxiliary fuel e.g. natural gas, advanced sludge treatment has to be carried out in order to raise the amount of dry matter content and thus to decrease the water content. Thus a selfreliant combustion as shown in Figure 4: is more likely to be performed and an improvement of its $\mathrm{CO}_{2}$ balance will come along with it. In case of self-reliant combustion, auxiliary fuel is necessary only to start up the combustion plant.

To produce self-reliant combusting sludge, a dry matter content of $35 \%$ to $45 \%$ for mixed raw sludge and $45 \%$ to $55 \%$ for digested sludge has to be achieved by means of dewatering and potentially drying. It depends on the water distribution in the sludge and the kind of dewatering whether drying is necessary or not.

In this connection it is necessary to be aware of the water distribution in the sludge. According to [1], the following types of water can be differed:

- $\quad$ interspace water (can be removed by gravity thickening),

- $\quad$ capillar water (can be removed by pressure filter or centrifuge),

- $\quad$ adsorption and inner water (can be removed by thermal energy).

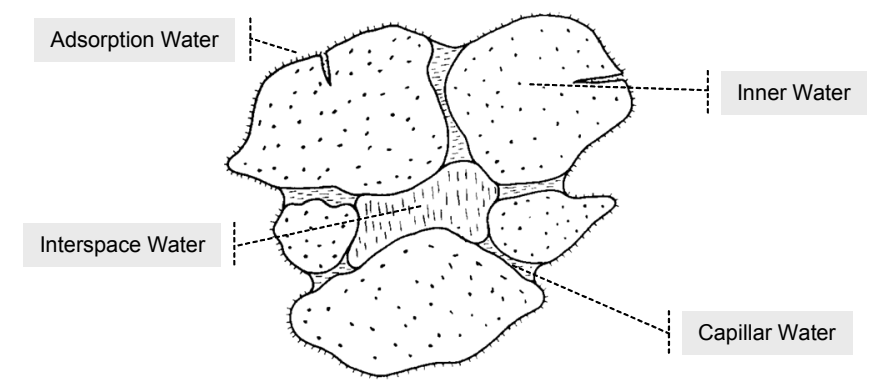

Figure 3: Water distribution in sludge [1].

Removal of interspace and capillar water can be achieved by simple and cheap dewatering. The maximum degree of dewatering however depends on the amount of adsorption and inner water. Thus, to raise the dry matter content, treatment technique has to be selected that reduces the amount of adsorption and inner water.

One possibility to increase the efficiency of the dewatering process and making drying dispensable is thermal disintegration which takes place before dewatering. Thermal disintegration can be categorized into three groups:

- frozen conditioning below freezing point (no implementation known),

- low thermal disintegration between $60^{\circ} \mathrm{C}$ and $80^{\circ} \mathrm{C}$,

- high thermal disintegration between $180^{\circ} \mathrm{C}$ and $230^{\circ} \mathrm{C}$.

Since high thermal disintegration is said to cause inhibitors, which could stop reactions within the waste water cleaning process [2], the low thermal disintegration was selected. In order to realize this process, in the first step a "made-to-measure" heat exchanger was designed which will preheat the sludge by means of hot water. 
In recent measurements at a big WWTP a dry matter content of about $33 \%$ was achieved by dewatering of mixed raw sludge. This value is very close to the range of the dry matter content at which a self reliant combustion can be expected. Therefore a process with improved dewatering was designed, where the sludge is heated up, dewatered and afterwards combusted.

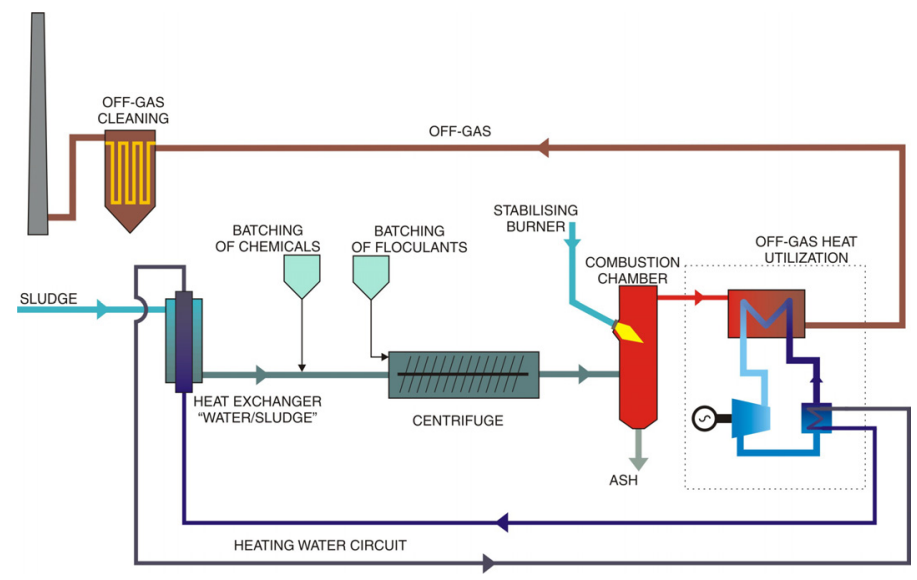

Figure 4: Design of improved sludge combustion process.

This process could be situated directly at the waste water treatment plant where mixed raw sludge is heated up to approximately $55^{\circ} \mathrm{C}$, centrifuged and afterwards combusted in a fluidized bed reactor or rotary kiln.

\section{Measurements of thermophysical sludge properties}

Physical properties of municipal sludge belong among the most important input data for design calculation of sludge preheater. Unfortunately, access to them in the open literature sources is not common.

Municipal sludge physical properties, namely rheological properties, were previously discussed in several publications, but usually these works mentioned only digested (anaerobically stabilised) and/or activated sludge. Only very few studies, e.g. [3] deal with rheologic behaviour of primary waste water sludge, but none described the properties of mixed raw sludge. Also the temperature range, in which data were available, was insufficient. For these reasons, measurements of:

- dynamic viscosity,

- specific heat capacity,

- density

were carried out for temperatures from $20^{\circ} \mathrm{C}$ to $50^{\circ} \mathrm{C}$. The sludge samples were taken from two different sewage plants with dissimilar characters of clarified waste water. The first one is a WWTP belonging to a city with population of approximately half a million inhabitants (WWTP 1). Further samples were taken 
from the WWTP which is operated to satisfy the demand of city with approximately 5\% less inhabitants compared to the previous one (WWTP 2).

In Figure 5: and 6 rheograms of mixed raw sludge from the above mentioned waste water treatment plants are shown. The comparison of these two figures outlines that sludge properties from different waste water treatment plants are not comparable.

The shear stress of sludge has a big dependence on the temperature where as the shear stress decreases while temperature increases. Further, the viscosity of sludge is much higher than water and cannot be compared with water because sludge cannot be considered as Newtonian liquid.

The specific heat capacity hardly depends on the temperature and can be compared with water in the first approach.

Sludge density decreases with temperature. In comparison with water, sludge density is slightly higher and shows a bigger dependence on the temperature.

More information about the measurement equipment, measurement procedure and more detailed values can be found in [4].

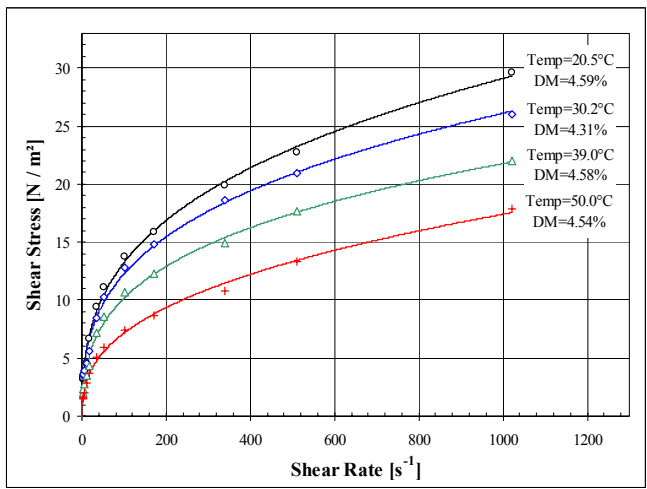

Figure 5: $\quad$ Shear stress vs. shear rate (sludge from WWTP 1).

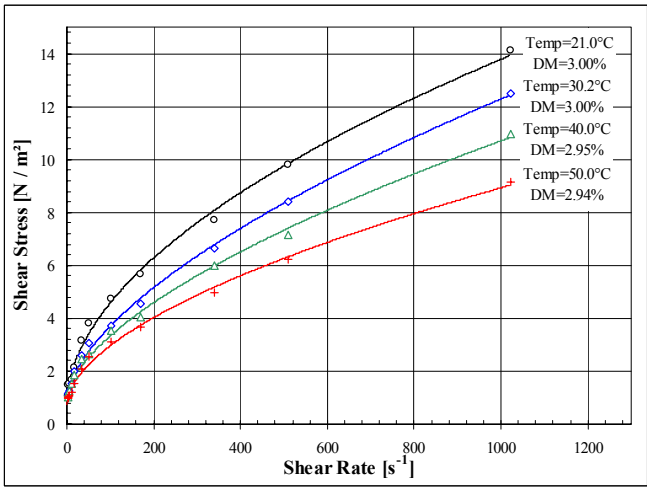

Figure 6: Shear stress vs. shear rate (sludge from WWTP 2). 


\section{Description of heat exchanger design}

The "made-to-measure" heat exchanger had to meet the following requirements:

- small built-up area,

- large heat transfer area,

- easy maintenance,

- easy to clean on the sludge side.

Sludge from municipal waste water treatment plants is a non-Newtonian, adhesive suspension and treatment of sludge in a heat exchanger is problematic. For this reason emphasis was made on the easy maintenance and cleaning on the sludge side.

To meet the requirements, a helical plate heat exchanger was designed. Figure 7 shows a heat exchange surface of a helical plate heat exchanger. It is a doublethreaded helix with a rectangular profile. The helix is wound around the central pipe and is divided into an open and closed part. The bending shape of the canal has a positive influence on its self-cleaning abilities. Through the close part of the helix, water is pumped bottom-up. In order to reduce the gravimetric part of pressure drop, sludge flows top-down. Since the sludge flows through the open part of the helix, the helix can be taken out of the exchanger shell and the area of heat exchange on the side of the sludge can be easily cleaned.

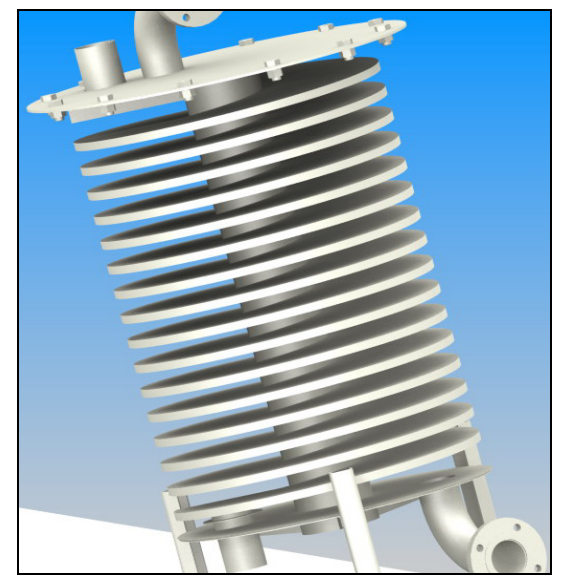

Figure 7: Novel design of "water-sludge" heat exchanger.

The course of development of a heat exchanger for "water-sludge" applications started with analytic calculations. General equations for heat balancing and heat transfer are used similarly as in the design of any other heat exchanger. However, the novel geometry required new equations for heat transfer coefficient $(\alpha)$ and pressure drop $(\Delta \mathrm{p})$ calculations. Suitable equations have not been found in the literature and so it was necessary to consider geometric and hydraulic similarity with other, mostly conventional heat exchanger types. 
The derivation of model equations for the new helical plate heat exchanger was based on the fact that both media flow through rectangular cross-sections as in plate-type heat exchangers, but with curvature, which is known from helical tubes. Therefore, model equations for the following heat exchangers have been considered:

A heat exchanger with helical tubes [5] (instead of pipe diameter $d$ was used hydraulic diameter $d_{h}$ ); plate-type heat exchanger with smooth plates expression derived using data published in [6]; plate-type heat exchanger with smooth plates and correction for curvature [7].

The derivation of model equations was done using several simplifying assumptions. These included the following: sludge was considered to be a Newtonian fluid, leakage stream of sludge between the exchanger shell and the water channel is negligible (the small dilatation gap is assumed blocked by highly viscous sludge), and width (radial dimension) of both channels is assumed equal.

In the first step, the properties of sludge were only theoretically determined by amending properties of water. The values were amended to be less advantageous for heat exchanger operation. After taking into account the measured properties of sludge (specific heat capacity, dynamic viscosity and density) the laminar flow in the sludge duct was identified and consequently had a very low heat transfer coefficient. In order to obtain the necessary outlet sludge temperature, the area of heat exchange had to be increased. For this reason the calculated height of the heat exchanger became practically unfeasible.

The preliminary model equations derived for the thermal and hydraulic calculation of the new helical plate heat exchanger and their detailed description may be found in [8].

After the dimension modifications a technically and economically feasible model was found. This model is shown in Figure 8:. The main modification of heat exchanger design was made in diameter of the central tube. The diameter was increased as well as the heat exchange surface.

In order to evaluate the accuracy of the obtained model, the next task was to analyze the model in CFD [9]. Thus the helix of the heat exchanger was modeled in FLUENT V6 and the accuracy of the mathematical model was verified for fluid velocities, pressure drop and temperature distribution.

Flow field analysis led to the conclusion that in the hot stream (water) turbulent flow takes place compared to the cold stream (sludge), where the flow is laminar.

The thermal and hydraulic analysis of the heat exchanger required design calculation without including the effects of fouling. This has not been considered in the detailed CFD model.

The temperature difference between the sludge outlet and inlet temperatures and water inlet and outlet temperatures was $41{ }^{\circ} \mathrm{C}$ and $11{ }^{\circ} \mathrm{C}$, respectively, provided fouling was neglected. The CFD model predicted a temperature difference between sludge outlet and inlet temperatures and water inlet and outlet temperatures that was $48{ }^{\circ} \mathrm{C}$ and $13{ }^{\circ} \mathrm{C}$, respectively. The disagreement can be readily explained as follows. 

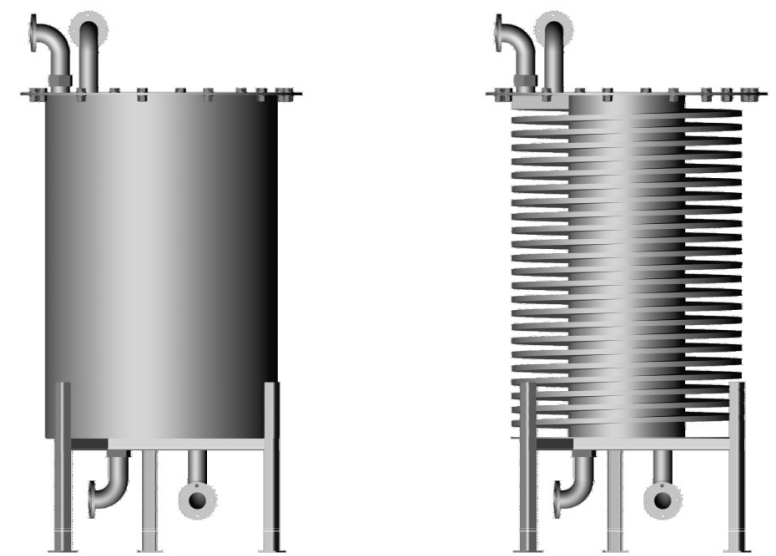

Figure 8: Improved design of water-sludge heat exchanger.
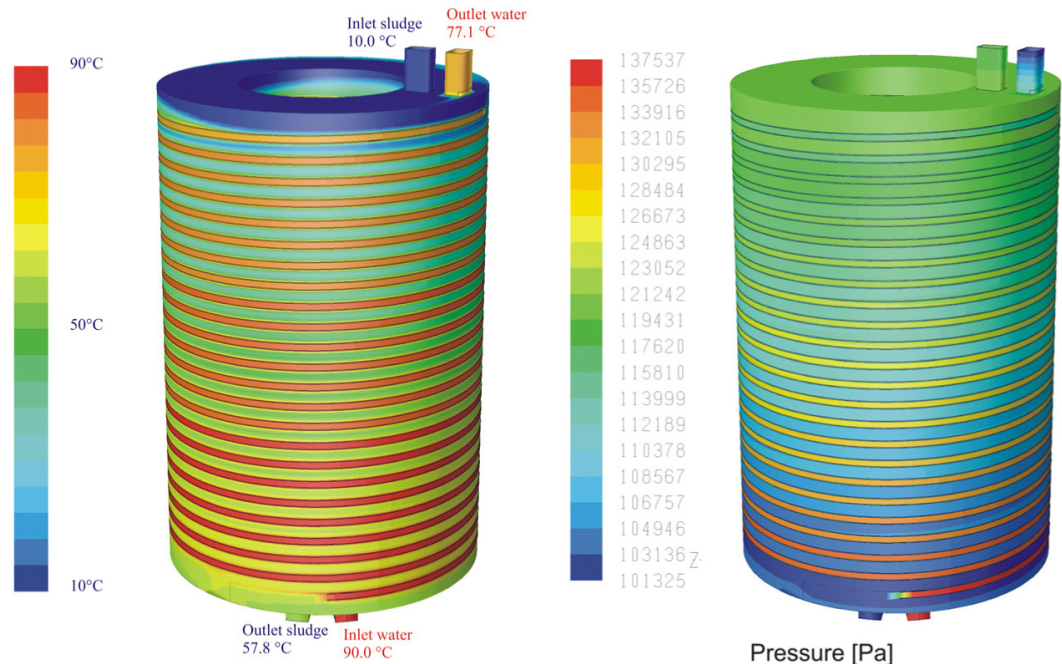

Figure 9: Thermal and hydraulic analysis of the heat exchanger.

Due to the water stream being fully turbulent and sludge stream laminar, even a small error in Nusselt number value for the sludge stream has a strong influence on the overall heat transfer rate (and on the outlet temperatures).

Pressure drops were also compared, and a large difference between analytical equations and the CFD models was observed. It is expected that the CFD predictions are more realistic due to a detailed description of flow, but no attempt to modify the equations for pressure drop calculation has been done with 
a view to the results obtained for the finest grid in the preliminary study. It is probable that pressure drop predicted using the standard wall function approach is less reliable than the results of the two-layer approach.

It is vitally important to measure all parameters including pressure drop on a pilot-scale facility which will be available in the near future. Measured data will be used for validation of a CFD model as well as for introducing correction factors into thermal and hydraulic calculations.

\section{Conclusion}

The analytical model was based on commonly used equations for heat exchanger calculations. Expressions for Nusselt number and friction factor were adopted considering similarity with other heat exchanger types.

Sludge properties (composition, thermo physical properties) are the most important input data for novel heat exchanger design calculations as well as for preparing heat balance of sludge incineration. The properties of sludge from a certain plant can be quite different compared to those coming from another. Knowledge of thermophysical sludge properties is essential for the basic design of a heat exchanger. Therefore, measurements of specific heat capacity, density and dynamic viscosity of the sludge are necessary from specific waste water treatment plants.

The analytical model for design calculations of the heat exchanger was compared with numerical simulation using CFD. Analysis of results shows relatively good agreement of the design model with CFD computations. Based on the comparison, a correction for Nusselt number in the sludge stream was proposed.

Pressure drops predicted by the analytical model using non-validated equations are significantly higher (almost twice) than those, predicted by CFD. Due to lower reliability of the pressure drops prediction by CFD (demonstrated on a very fine grid in the tests), it was concluded that corresponding correction of the design equations is not desirable. In order to outline these results, measurements on a pilot-scale heat exchanger will provide real data which will be compared with the calculation results. Based on this comparison the analytic expressions will be corrected and used for further heat exchanger design.

\section{Acknowledgement}

We gratefully acknowledge financial support of the Ministry of Education, youth and sports of the Czech Republic within the framework of research plan No. MSM 0021630502 "Waste and Biomass Utilization focused on Environment Protection and Energy Generation".

\section{References}

[1] Batel W.; Menge und Verhalten der Zwischenraumflüssigkeit in körnigen Stoffen; Chemie-Ingenier-Technik 1961 Nr. 3 
[2] Dritter Arbeitsbericht der ATV/DVWK Arbeitsgruppe "Klärschlammdisintegration"

[3] Bhattacharya S. N., 1981, Flow characteristics of primary and digested sewage sludge, Rheologica Acta 20, pp. 288-298.

[4] Elsäßer, T.; et al.; Thermal dependences of physical aspects of sewage sludge; proceeding on CD-Rom, PRES 2006, Prague

[5] Verein Deutscher Ingenieure, Wärmeatlas, VDI - Verlag GmbH, Düsseldorf (1987)

[6] Kays W. M., London A. L., Compact Heat Exchangers, McGraw-Hill Book Company, New York (1984)

[7] Chapman A.J., 1989, Heat Transfer, Macmillan Publishing Company, New York

[8] Kilkovský, B.; et al.; Research and Development of Heat Exchangers "Water-Sludge", 9th Conference on Process Integration, Modelling and Optimisation for Energy Saving and Pollution Reduction Pres 2006, Proceedings on CD-ROM, Prague, Czech Republic

[9] Piskovsky, M.; Analysis of helical heat Exchange water-sludge by CFD; Heat SET 2007; Accepted for publication

[10] Houdkova, L.; et al.; Impact of Sewage Sludge Dewatering on Economic and Environmental Balance of High Capacity Waste Water Treatment Plant; PRES 2006

[11] Boráň J., Houdková L., Stehlík P., 2005a, Waste as alternative fuel. First International Conference on Thermal Treatment and Resource Utilization of Wastes. Beijing, China, pp. 179-185.

[12] Boráň J., Houdková L., Ucekaj V., Št’asta P., Stehlík P., 2005b, The Analysis of Energy Utilization in Processes for Sewage Sludge Treatment. 8th Conference on Process Integration, Modelling and Optimisation for Energy Saving and Pollution Reduction. Milano, Italy: AIDIC, pp. 139144. ISBN: 88-900775-8-1.

[13] FLUENT 6.3.26, 2006, User`s Guide, Fluent Inc., Lebanon, USA

[14] Hewit G.F. (ed.), 1998, Heat Exchanger Design Handbook, Begell House, Inc., New York

[15] Hewit G.F. (ed.), Heat Exchanger Design Handbook 1998, Begell House, Inc., New York (1998)

[16] Smith E. M., Thermal Design of Heat Exchangers, John Wiley \& Sons, Chichester (1997)

[17] Stulir R., Stehlik P. and Oral J., 2003, Efficient Equipment with Special Heat Exchanger for Thermal Treatment of Polluted Air - Experiments, Computations, Applications, Heat Transfer Engineering, 24, pp. 60 - 69 